\title{
Optimization of Abs 3D-Printing Method and Parameters
}

\author{
Paweł Żur, Alicja Kołodziej*, Andrzej Baier and Grzegorz Kokot
}

Faculty of Mechanical Engineering, Silesian University of Technology, Gliwice, Poland

\begin{tabular}{|c|c|}
\hline ARTICLE INFO & ABSTRACT \\
\hline $\begin{array}{l}\text { Keywords: } \\
\text { 3D-printing } \\
\text { ABS } \\
\text { FDM } \\
\text { Filament } \\
\text { Tensile test }\end{array}$ & $\begin{array}{l}\text { The paper presents research on the method of 3D-printing ABS } \\
\text { (Acrylonitrile butadiene styrene). Series of specimens were 3D- } \\
\text { printed in FDM (Fused Deposition Modelling) technology with } \\
\text { variable parameters. The influence of the following parameters has } \\
\text { been checked: temperature of printing and infill density. Moreover, } \\
\text { the material properties of raw, unprocessed ABS have been } \\
\text { inspected. The tensile strength of specimens and Young's modulus } \\
\text { have been determined in a static tensile test. Tests were carried out } \\
\text { in compliance with the ASTM D638-14 standard. Obtained results } \\
\text { were then compared with the material datasheet. Optimum printing } \\
\text { method has been defined. The carried out research resulted in } \\
\text { optimizing the printing method for ABS vehicle parts applied in } \\
\text { Silesian Greenpower electric car. The car has been developed by } \\
\text { students of The Silesian University of Technology in Gliwice, } \\
\text { Poland as an interfaculty students' project. Results of the tensile test } \\
\text { research have been analysed and discussed and conclusions have } \\
\text { been presented in the following article. }\end{array}$ \\
\hline
\end{tabular}

\section{Introduction}

Additive manufacturing is relatively new technology, which has been invented in the 1980s and developed dynamically in the last two decades. Additive manufacturing technologies, now more commonly referred to as 3D-printing, have gained acceptance and popularity in manufacturing, educational, and home-use settings (Perez, Roberson, \& Wicker, 2014; Baier, Zur, Kolodziej, Konopka, \& Komander, 2018). Material extrusion 3D printers similar in function to the trademarked fused deposition modelling (FDM) process is the most common type of equipment used in 3DP and rely on a process by which a polymeric filament is extruded and deposited in a layer-by-layer manner until a 3D object is created. However, there are limited applications of FDM 3D printing due to fact, that the mechanical strength of the FDM printed products are usually worse compared with injection moulding due to their weakness points between the layers (Weng, Wang, Senthil, \& Wu, 2016).

ABS (Acrylonitrile Butadiene Styrene) has a long history in the 3D printing technologies. This material was one of the first plastics to be used with industrial 3D printers. Many years later, ABS is still a very popular material thanks to its low cost and good mechanical properties. ABS is known for its toughness and impact resistance, allowing to print durable parts that will hold up to extra usage and wear. ABS also has a higher glass transition temperature, which means the material can withstand much higher temperatures before it begins to deform. This makes ABS a great choice for outdoor or high temperature applications (Simplify3D ABS overview [retrieved 2019-10-20]). The work presented in this research explored the effect of applying different ABS printing parameters such as printing temperature and infill density in order to improve tensile strength.

\footnotetext{
* Corresponding Author E-Mail Address: alickol96@gmail.com 
Silesian Greenpower is a students' project of which aim is to design and build an electric race car. Based on the results obtained in analysis new solutions, constructions and parts are being applied in the vehicle. Some parts of the Silesian Greenpower vehicles are 3D-printed - e.g. wheel fairing and mirror housing. This method allows customizing the shape of an element and its manufacturing. The aim of the research is the optimization of 3D-printing technology of ABS in order to reduce weight and printing time of the driver's seat used in the electric vehicle., presented in Figure 1. (Żur, Baier, \& Kolodziej, 2019; Żur, Kołodziej, \& Baier, 2019).

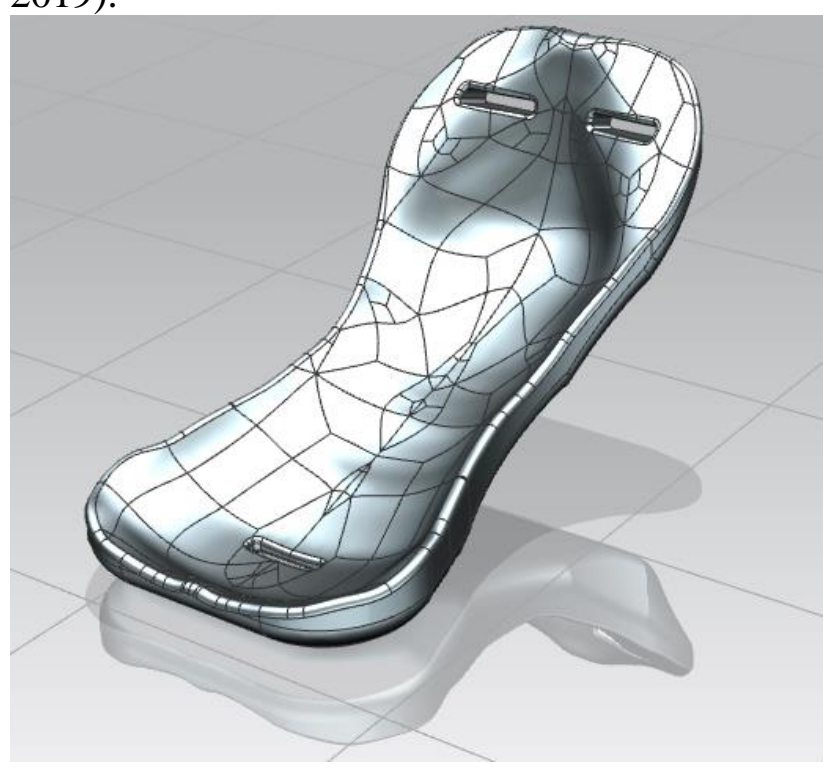

Figure 1. Driver's seat applied in SG vehicle

\section{Material - ABS}

One of the most common materials utilized by material extrusion 3D printing is acrylonitrile butadiene styrene (ABS) (Perez et al., 2014). The most important mechanical properties of ABS are impact resistance and toughness. The final properties will be influenced to some extent by the conditions under which the material is processed to the final product - in this case - the temperature of printing and infill density (Harper, 1975). Obtained results have been compared to material datasheet provided by the producer of the 3D-printing filament. The filament used in the test was smart ABS by Spectrum Filament. Material data have been presented in Table 1.

Table 1.

\begin{tabular}{lll} 
Material data & & \\
\hline Infill & $50 \%$ & $100 \%$ \\
Tensile strength [MPa] & 15,8 & 23,8 \\
Force at break [MPa] & 15,7 & 23,6 \\
Elongation at max force & 8,8 & 5,3 \\
[\%] & & \\
Elongation at break [\%] & 11,0 & 13,3 \\
Young's modulus & 307,8 & 453,8 \\
\hline
\end{tabular}

Source: Spectrum Filaments smart ABS - Technical datasheet

\subsection{Tensile tests}

Tensile tests measure the force required to break a specimen and the extent to which the specimen stretches or elongates to at breaking point. Such tests allow obtaining stress-strain 
diagrams used to determine the tensile modulus of the material. The resulting test data can help specify optimal materials, design parts to withstand application forces, and provide key quality control checks for materials (Intertek Tensile testing of Polymers and Composite Materials [retrieved 2019-10-20).

\section{Test objective}

The aim of the research was a tensile test of 3D-printed ABS (Acrylonitrile butadiene styrene) samples. Series of specimens were modelled in compliance with ASTM D638-14 standard. Following parameters have been inspected - the printing temperature $\left(230^{\circ} \mathrm{C}\right.$ and $260^{\circ} \mathrm{C}-$ lowest and highest admissible temperature) and infill density (10\%, 25\%, 50\% and 100\%). Adopted infill pattern was honeycomb, due to its higher tensile strength compared to lattice pattern (Żur, Kołodziej, Baier, \& Borek, 2019). Each sample had 5 specimens. Parameters of samples were presented in Table 2.

Table 2.

\begin{tabular}{lll}
\multicolumn{2}{l}{ Parameters of samples } \\
\hline Sample & Temperature $\left[{ }^{\circ} \mathbf{C}\right]$ & Infill density [\%] \\
\hline Sample 1 & 230 & 10 \\
Sample 2 & 230 & 25 \\
Sample 3 & 230 & 50 \\
Sample 4 & 230 & 100 \\
Sample 5 & 260 & 10 \\
Sample 6 & 260 & 25 \\
Sample 7 & 260 & 50 \\
Sample 8 & 260 & 100 \\
\hline
\end{tabular}

Shape of inspected specimens has been presented in Figure 2.

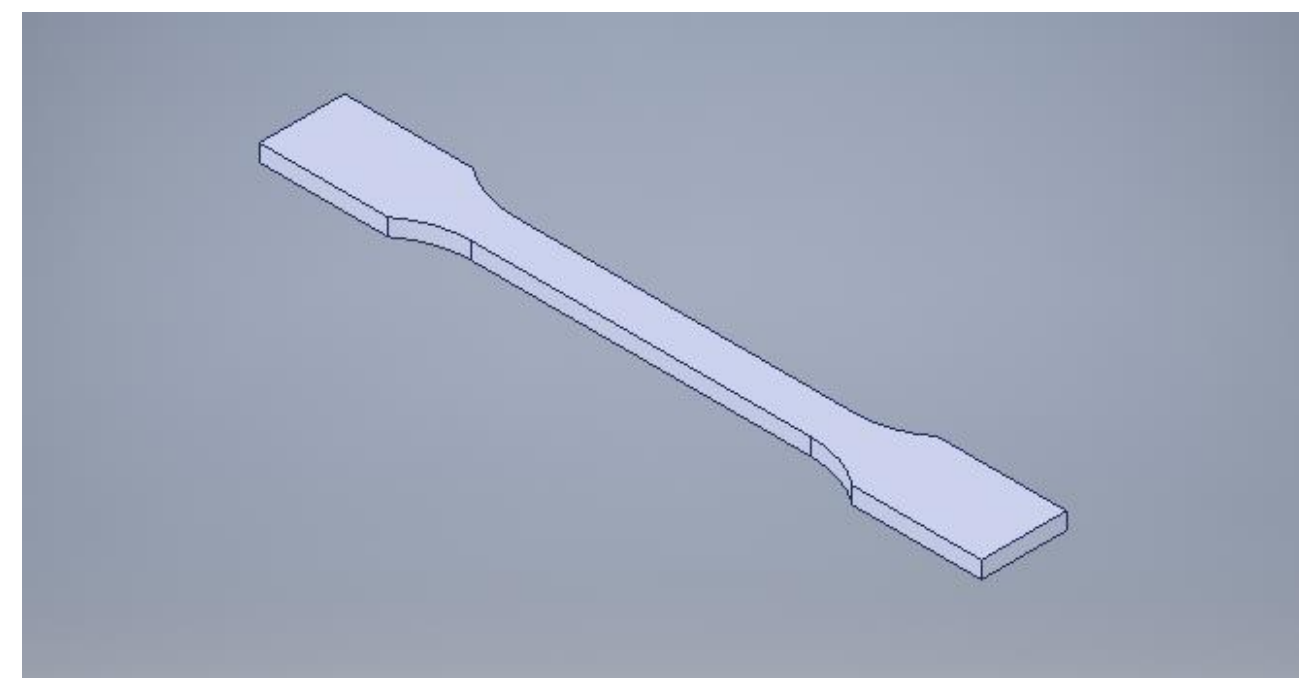

Figure 2. Specimen type

The test was carried out in compliance with ASTM-638-14 standard. A machine used for the test was MTS Insight $10 \mathrm{kN}$. The test speed was $5 \mathrm{~mm} / \mathrm{min} .40$ specimens have been inspected. Additionally, parameters of the unprocessed filament have been inspected. Filament has been installed in the machine using special crimp-fitting clamps. The test stand with filament installed has been presented in Figure 3. 


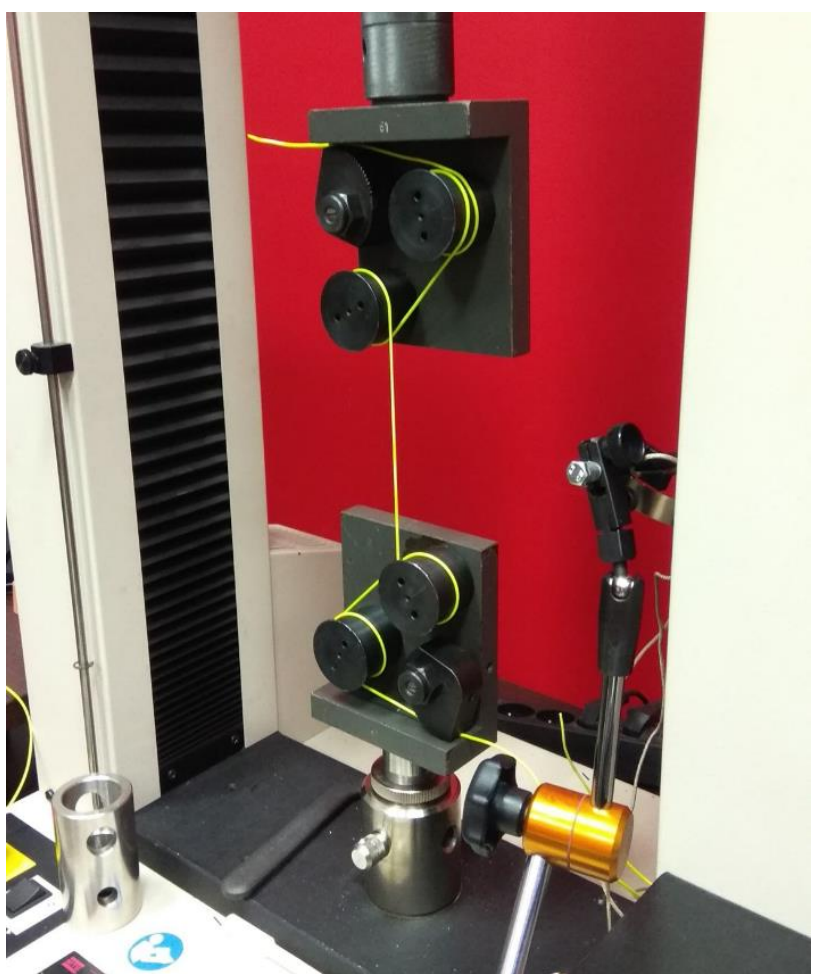

Figure 3. Test stand with filament installed

\section{Results and Discussion}

The average test results for each of the 8 samples were presented in Table 3. Stress-strain diagram for each sample has been presented in Figure 4 .

Table 3.

Average test results for each sample

\begin{tabular}{ccccccc}
\hline Sample & Area $\left[\mathbf{m m}^{2}\right]$ & $\begin{array}{c}\text { Peak Load } \\
{[\mathbf{N}]}\end{array}$ & $\begin{array}{c}\text { Peak Stress } \\
{[\mathbf{M P a}]}\end{array}$ & $\begin{array}{c}\text { Tensile } \\
\text { strength } \\
{[\mathbf{M P a}]}\end{array}$ & $\begin{array}{c}\text { Strain at } \\
\text { break } \\
{[\mathbf{m m} / \mathbf{m m}]}\end{array}$ & $\begin{array}{c}\text { Young's } \\
\text { modulus }\end{array}$ \\
\hline Sample 1 & 40 & 755 & 18,9 & 18,89 & 0,085 & 264 \\
Sample 2 & 40 & 810 & 20,2 & 20,24 & 0,090 & 295 \\
Sample 3 & 40 & 910 & 22,7 & 22,74 & 0,091 & 342 \\
Sample 4 & 40 & 1361 & 34,0 & 34,02 & 0,127 & 476 \\
Sample 5 & 40 & 727 & 18,2 & 18,16 & 0,085 & 269 \\
Sample 6 & 40 & 788 & 19,7 & 19,71 & 0,089 & 288 \\
Sample 7 & 40 & 897 & 22,4 & 22,42 & 0,088 & 343 \\
Sample 8 & 40 & 1359 & 34,0 & 33,98 & 0,094 & 473 \\
Filament & 2,4 & 87 & 36,3 & 36,35 & 0,449 & 314 \\
\hline
\end{tabular}




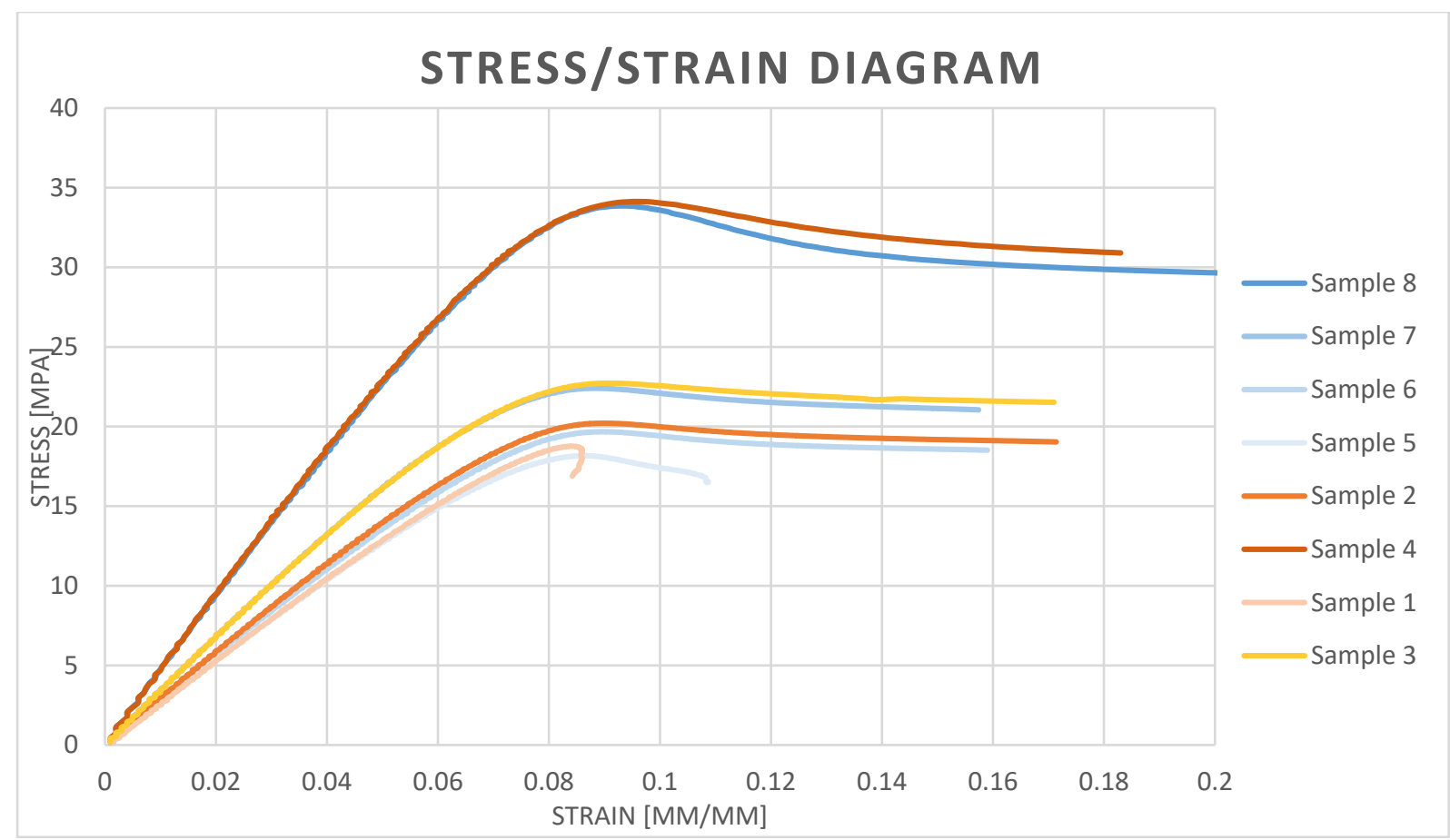

Figure 4. Stress-strain diagram

The standard relative deviation of $0.52 \%$ in maximum stress and $1.96 \%$ in Young's modulus, therefore, results obtained are accurate.

It can be seen, that Young's modulus varies between 264-476 MPa. Maximum forces applied for samples vary between 727-1361 N. Values of tensile strength are in the range of 18,1634,02 MPa.

Highest Young's modulus value and highest tensile strength among series represented samples 4 and 8 - both with $100 \%$ infill density - respectevily 476 and $473 \mathrm{MPa}$. As suspected, the lowest values of Young's modulus and tensile strength represent samples 1and 5-with lowest infill density - 264 and $269 \mathrm{MPa}$. Therefore, it can be concluded, that increasing infill density increases tensile strength.

Nonetheless, influence of increasing printing temperature is not unequivocal. Samples printed in $230^{\circ} \mathrm{C}$ represent higher or the same tensile strength values than samples printed a $260^{\circ} \mathrm{C}$.

The stress-strain diagram for ABS filament has been presented in Figure 5. Maximum applied force for filament was $87 \mathrm{~N}$. The unprocessed filament represents highest tensile strength values among all tested samples - 36,35 MPa. The unprocessed filament has Young's modulus of $314 \mathrm{MPa}$ - which is close to the value of Young's modulus of samples printed with $50 \%$ infill density. The sharp edges visible in the graph were caused by the filament stretching on clamps during the tensile test. 


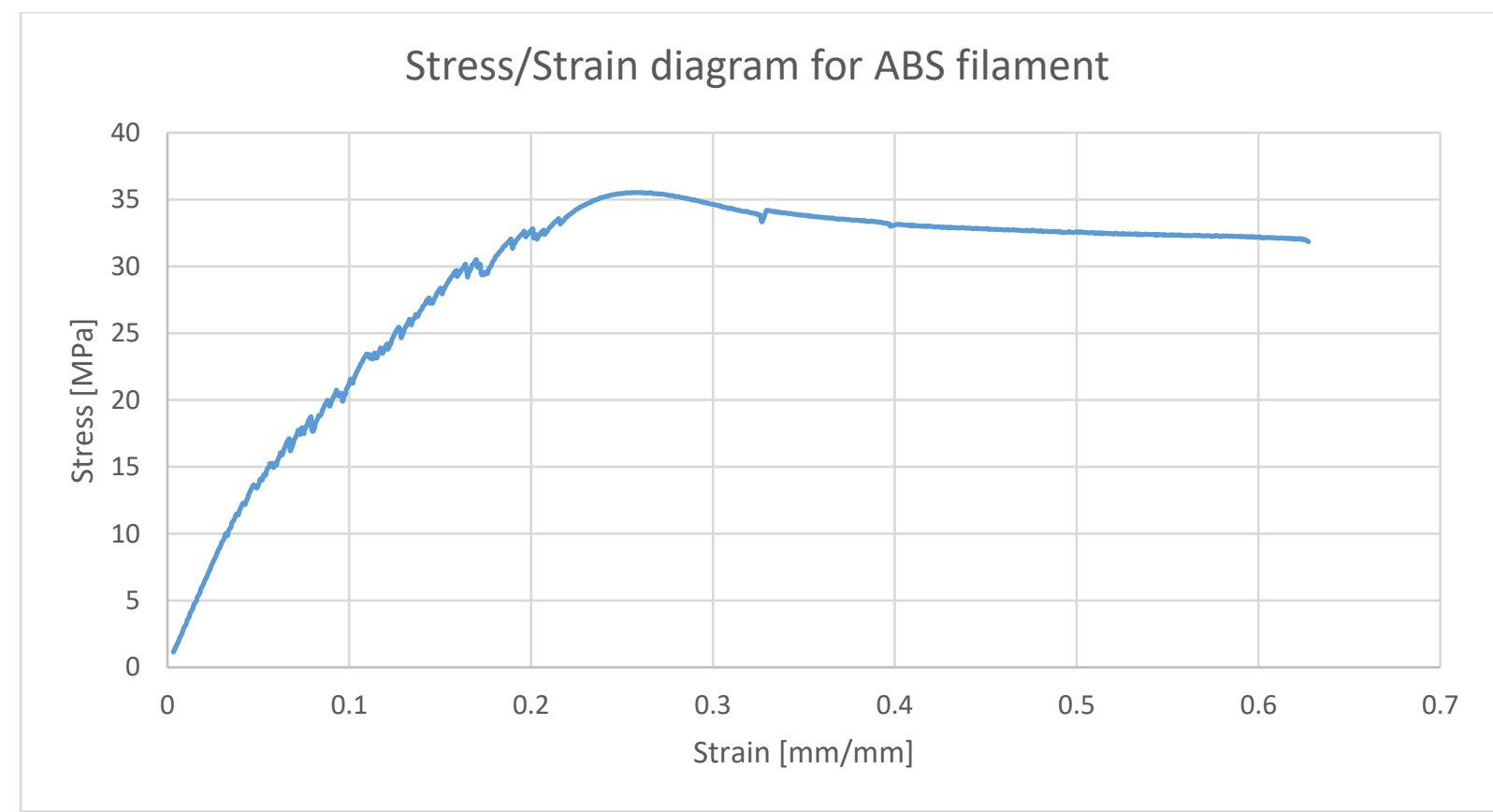

Figure 5. Stress/Strain diagram for ABS filament

After carried out analysis of the weight of the part and printing time, it was concluded that applying $25 \%$ infill rate reduces the tensile strength of the part only by $12 \%$ compared to $50 \%$ infill, while the weight of the item has been reduced by $50 \%$ and printing time by $33 \%$ compared to $50 \%$ infill, which is a significant saving in manufacturing costs. The results have been presented in Figure 6.
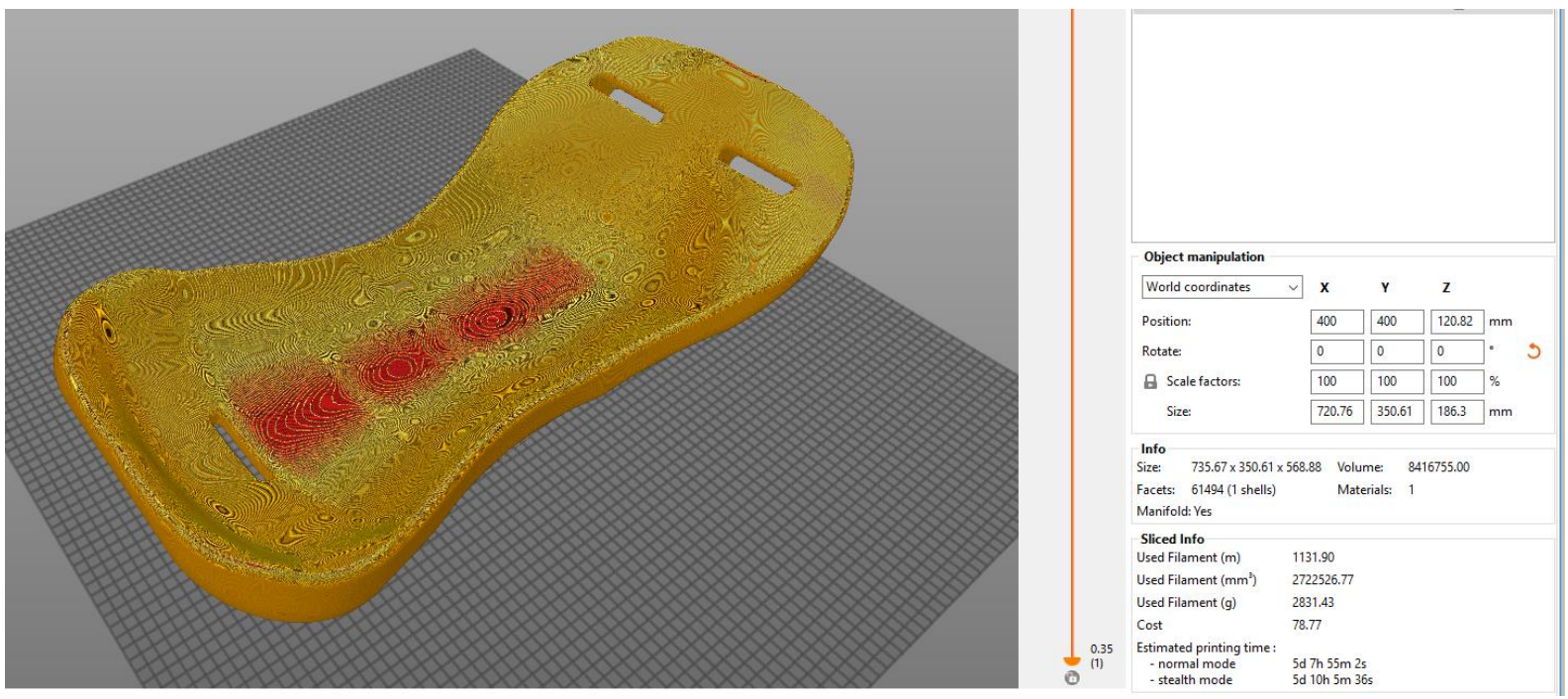

Figure 6. Printing time and weight of the part analysis

Using the Finite Element Method analysis, stress distribution in the specimen was shown in Figure 7. The specimen was fixed as in a static tensile test. A force of $1360 \mathrm{~N}$ was applied. The maximum stress was $34.92 \mathrm{MPa}$ which coincides in the actual test at full infill. 


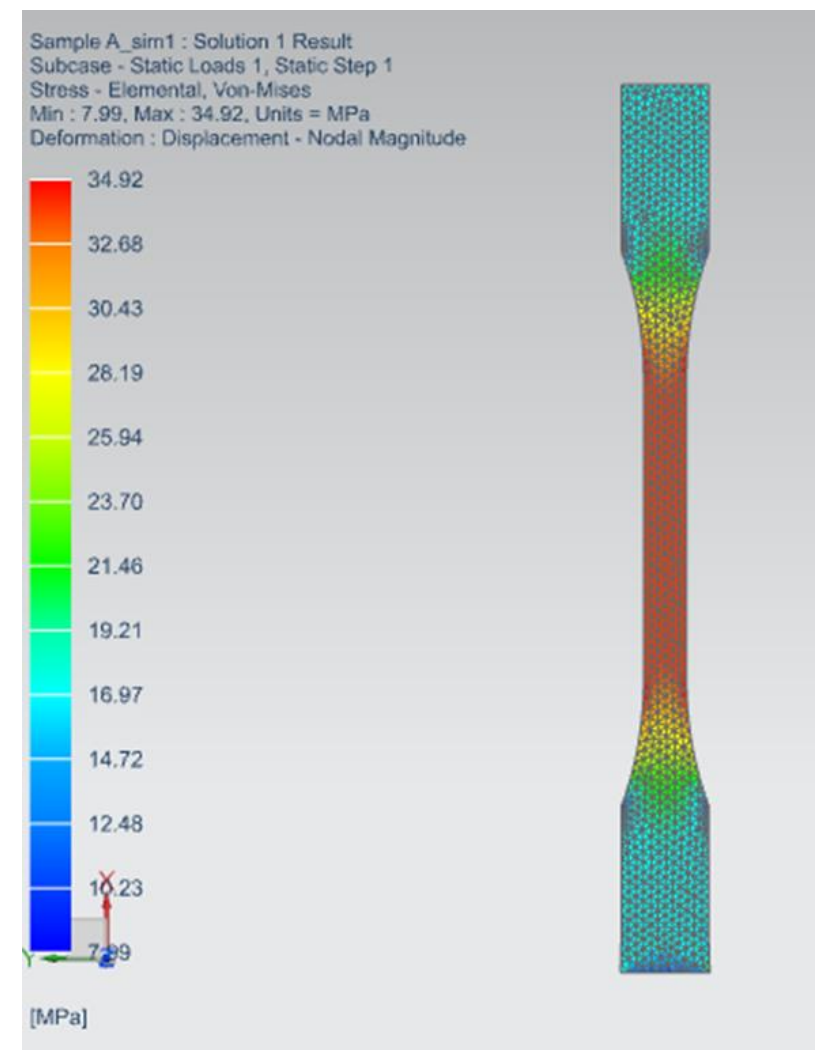

Figure 7. Stress distribution in specimen

\section{Conclusions}

1. Due to the lower printing temperature, a better tensile strength of a given filament have been obtained - the printing temperature has a greater impact at lower infill density, the difference in favour of a lower temperature is about $4 \%$.

2. Honeycomb infill pattern allows to obtain much greater tensile strength values than for lattice infill pattern - about $50 \%$ higher maximum stress.

3. With infill density of $50 \%$ or more, Young's modulus is higher than for unprocessed filament (314 MPa vs $342 \mathrm{MPa}$ ).

4. Lower values of Young's modulus and maximum stress in material datasheet may be caused by applying cooling rate while printing.

5. The use of full infill increases tensile strength up to $51 \%$ compared to an infill density of $50 \%$.

6. The use of a $25 \%$ infill reduces the tensile strength by only $12 \%$ compared to a $50 \%$ infill.

7. Printing with honeycomb infill pattern increases the printing time, in some cases, by almost $45 \%$.

\section{References}

Baier, A., Zur, P., Kolodziej, A., Konopka, P., \& Komander, M. (2018, August). Studies on optimization of 3D-printed elements applied in Silesian Greenpower vehicle. In IOP Conference Series: Materials Science and Engineering (Vol. 400, No. 2, p. 022010). IOP Publishing.

Harper, C. A. (1975). Handbook of Plastics and Elastomers 1McGraw-Hill. New York, 19752, 56.

Intertek Tensile testing of Polymers and Composite Materials [retrieved 2019-10-20] 
Perez, A. R. T., Roberson, D. A., \& Wicker, R. B. (2014). Fracture surface analysis of 3Dprinted tensile specimens of novel ABS-based materials. Journal of Failure Analysis and Prevention, 14(3), 343-353.

Simplify3D ABS overview [retrieved 2019-10-20]

Weng, Z., Wang, J., Senthil, T., \& Wu, L. (2016). Mechanical and thermal properties of ABS/montmorillonite nanocomposites for fused deposition modeling 3D printing. Materials \& Design, 102, 276-283.

Żur, P., Baier, A., \& Kolodziej, A. (2019, April). Influence of Selected Parameters of the Motor Controller on the Current Characteristics of the DC Brush Motor Used in the Silesian Greenpower's Vehicle. In IOP Conference Series: Materials Science and Engineering (Vol. 520, No. 1, p. 012010). IOP Publishing.

Żur, P., Kołodziej, A., Baier, A. \& Borek W. (2019). Influence of 3D-printing Parameters on Mechanical Properties of PLA defined in the Static Bending Test. European Journal of Engineering Science and Technology, 2(1), 65-70.

Żur, P., Kołodziej, A., \& Baier, A. (2019). Finite Elements Analysis of PLA 3D-printed Elements and Shape Optimization. European Journal of Engineering Science and Technology, 2(1), 59-64. 